\title{
Mapping groundwater availability and adequacy in the Lower Zambezi River basin
}

\author{
Blanca Pérez-Lapeña ${ }^{1}$, Francisco Saimone ${ }^{1}$, and Dinis Juizo ${ }^{1,2}$ \\ ${ }^{1}$ Salomon Lda., Maputo, Mozambique \\ ${ }^{2}$ Civil Engineering, Eduardo Mondlane University, Maputo, Mozambique \\ Correspondence: Francisco Saimone (francisco.saimone@gmail.com)
}

Received: 10 November 2017 - Accepted: 11 December 2017 - Published: 29 May 2018

\begin{abstract}
Groundwater plays an important role as a source of water for various socio-economic uses and environmental requirements in the lower Zambezi basin in Mozambique. Hence it is important to know its availability and adequacy in space to inform decision making for sustainable water management practices. For a derivation of a Groundwater Availability map and a Groundwater Adequacy map we adapted the DRASTIC methodology in a GIS environment to determine how different parameters, such as precipitation, topography, soil drainage, land use and vegetation cover, aquifer characteristics and groundwater quality affect (i) groundwater recharge on a long-term sustainable basis, (ii) the short-term abstraction potential and (iii) the long-term adequacy of groundwater utilization for domestic use. Results showed that groundwater availability in the Zambezi basin varies mostly from medium to low, with highest potential along the perennial rivers and in the delta where it plays a crucial role in environmental preservation. The southern margin of the Zambezi River shows low groundwater availability and also presents low adequacy for domestic use due to poor groundwater quality. The results from this study will be used in determining the most promising future development pathways and select the most attractive strategic development plans of the Mozambican government for the Lower Zambezi basin.
\end{abstract}

\section{Introduction}

Groundwater is an essential source of water for various socio-economic uses in the lower Zambezi Basin (World Bank, 2009). It is also the only source of water supply to rural communities and the main source to two provincial capital cities in the center of the country, i.e. Quelimane (aquifer of Licuári) and Tete/Moatize (aquifers of the Nhartanda valley and those located on the banks of the Revúboè River). Groundwater also plays a crucial role in the preservation of valuable ecosystems in the basin. In semi-arid areas groundwater is an important resource for drought mitigation (Foster and Tyson, 2013). In contrast, recent trends of intensification of mining activities in the Zambezi valley bring several challenges for groundwater management, related to lowering of groundwater levels and the infiltration of acid and highly mineralized waters (Pondja et al., 2017).
It is within this context that it is necessary to evaluate the groundwater potential and the risks associated to its exploitation.

The presence, quantity, and quality of groundwater is related to geological, structural, climatic, morphological, surface drainage, chemical content, and land use/land cover factors and several models have emerged that seek to establish the groundwater potential in a basin (Ganapuram et al., 2009). This study followed a similar approach as the weighing method originally developed for groundwater contamination risk analysis (DRASTIC, Aller et al., 1987). Based on the work by SWECO (2004) and Plancenter (2008), an adaptation and extension of the method is presented to incorporate key parameters that affect groundwater recharge and its quality, and thus, indicate groundwater availability and adequacy. In the remaining of this paper we refer to groundwater as fresh water occurring in the saturated zone. 


\section{Methodology}

\subsection{Study area}

The study area of this project covered the Zambezi river basin in Mozambique. The basin is the richest region in Mozambique in natural resources (due to its high potential in the agricultural, hydropower and mining sectors) as well as in tourism while the Delta is of high environmental importance. About four million people live within the boundaries of the Zambezi River basin, with the highest concentrations in the cities of Tete and Quelimane. Its climate varies from tropical wet in the Delta area, to tropical dry savanna in areas close to the Zambezi river and moderately humid, based on altitude, in the northern part of the basin. The general rainfall pattern shows a decrease from the coast to the most inland areas as a result of precipitation originating mostly from fronts and cyclones.

For the analyses, the basin was subdivided into 27 subbasins that were defined considering the main confluences and sections of the most important tributaries and imposing maximum sub-basin areas on the order of $10000 \mathrm{~km}^{2}$ and minimum areas in the order of $2500 \mathrm{~km}^{2}$ (Fig. 1).

\subsection{The extended approach}

The DRASTIC system is a widely used method to assess the vulnerability of groundwater resources to pollution. It is an overlay and index model designed to produce vulnerability scores by superimposition of environmental and geological thematic maps (Aller et al., 1987). In essence, the DRASTIC method is based on the hydraulic and hydrogeological characteristics of the aquifers. The DRASTIC method was adapted and extended in this study to evaluate the availability and viability of groundwater exploration. The following four categories and corresponding factors were considered in our approach:

1. the depth to the water table $(D)$, affecting the potential exploitation of groundwater;

2. the short-term abstraction potential $(P)$, governed by the aquifer material $(A)$ and associated productivities $(C)$;

3. the magnitude of groundwater recharge $(R)$ on a longterm basis, governed by the mean annual precipitation (MAP), slope $(T)$, soil infiltration $(S)$, and land use and land cover (LU/LC);

4. groundwater quality $(Q)$, affecting the adequacy of groundwater for domestic water supply.

Values in each factor were first divided into ranges. Each range was assigned a rate $p$ on a scale 1 to 10 and then each category was assigned a weight $w$ to quantify its relative importance in determining groundwater availability and

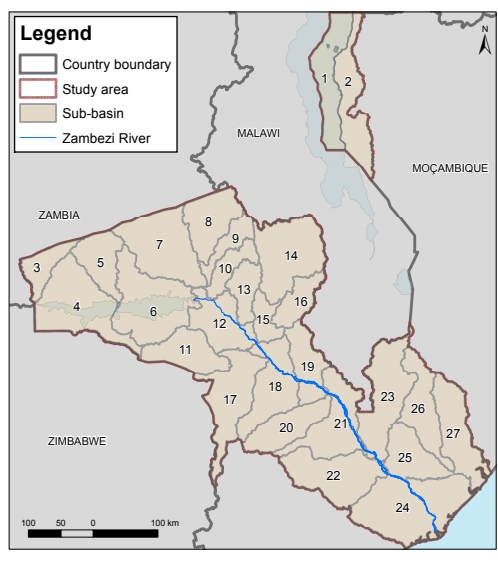

Figure 1. Study area and sub-basins.

adequacy for domestic use. Equation (1) was used to calculate the groundwater availability index and Eq. (2) was used to calculate the availability and adequacy index:

Availability index $=D_{p} \cdot D_{w}+P_{p} \cdot P_{w}+R_{p} \cdot R_{w}$

Availability and adequacy index $=D_{p} \cdot D_{w}+P_{p} \cdot P_{w}$

$$
+R_{p} \cdot R_{w}+Q_{p} \cdot Q_{w} .
$$

The analysis was carried out in a GIS environment to produce spatially varying indices as presented in the groundwater Availability map and the map of Availability and Adequacy of groundwater use for the study area.

\subsection{Hydrogeological categories}

\subsubsection{Depth to water table $(D)$}

A database was constructed containing all identified spatial data on boreholes until November 2016 for the study area. Data on groundwater levels was obtained from 1028 boreholes (depth in $\mathrm{m}$ ). The relationship between water depth values and the basin hydrogeology was first analysed by fitting a regression model to the (log-transformed) water depth data, using aquifer type as the dummy variable. After the analysis, we obtained a non-significant overall fit (at $\alpha=0.05$ ). The depth to water table map was determined spatially by interpolating the water depth values using the Inverse Distance Weighing algorithm, IDW. In this study, rates were adopted from Aller et al. (1987) and are presented in Table 1 and applied to create the map in Fig. 2a.

\subsubsection{Short-term abstraction potential $(P)$}

The data contained in the Hydrogeological Map of Mozambique at scale of 1:1000000 was used to assess the shortterm abstraction potential in the study area. The hydrogeological map contains information of (i) aquifer types and (ii) "yield classes" associated with each aquifer type. Types of aquifers, as described in the Hydrogeological map, are: 
Table 1. Ratings for factors/categories.

\begin{tabular}{|c|c|c|c|c|c|}
\hline $\begin{array}{l}\text { Factor } \\
\text { Depth to water (m) }\end{array}$ & Rate & $\begin{array}{l}\text { Factor } \\
\text { Slope }(\%)\end{array}$ & Rate & $\begin{array}{l}\text { Factor } \\
\text { Land use and land cover }\end{array}$ & Rate \\
\hline $0-1.5$ & 10 & $0-2$ & 10 & Irrigation cultivation & 9 \\
\hline $1.5-4.5$ & 9 & $2-4$ & 9 & Raifed cultivation & 8 \\
\hline $4.5-9.1$ & 7 & $4-7$ & 8 & Decidous shrubs; decidous & 7 \\
\hline $9.1-15.2$ & 5 & $7-12$ & 5 & grassland ( $2-5 \mathrm{~m}$ high); rice & \\
\hline $15.2-22.8$ & 3 & $12-18$ & 3 & cultivation, natural water bodies & \\
\hline $22.9-30.5$ & 2 & $>18$ & 1 & Everygreen shrubland; Everygreen & 6 \\
\hline$>30.5$ & 1 & & & grassland ( $2-5 \mathrm{~m}$ high $)$ & \\
\hline Short-term abstraction potential & & $\mathrm{EC}$ & & Shrub savanna & 5 \\
\hline Aquifer type $\mathrm{A}\left(>50 \mathrm{~m}^{3} \mathrm{~h}^{-1}\right)$ & 10 & $0-700$ & 10 & Miombo open; Mopane open; & 4 \\
\hline Aquifer type B $\left(>50 \mathrm{~m}^{3} \mathrm{~h}^{-1}\right)$; type A $\left(10-50 \mathrm{~m}^{3} \mathrm{~h}^{-1}\right)$ & 8 & $700-1500$ & 8 & $\begin{array}{l}\text { Decidous forest; Open shrub on temporarily } \\
\text { flooded land; Shifting vegetation; }\end{array}$ & \\
\hline Aquifer type A $\left(3-10 \mathrm{~m}^{3} \mathrm{~h}^{-1}\right)$, type $B\left(10-50 \mathrm{~m}^{3} \mathrm{~h}^{-1}\right)$ & 6 & $1500-7500$ & 3 & $\begin{array}{l}\text { Herbaceous vegetation temporarily flooded; } \\
\text { Evergreen forest; Tree crops; Tree savanna; }\end{array}$ & \\
\hline Aquifer type $\mathrm{C}\left(<1 \mathrm{~m}^{3} \mathrm{~h}^{-1}\right)$ & 3 & $>7500$ & 1 & Woodland temporarily flooded land & \\
\hline Soil infiltration & & $\begin{array}{l}\text { Recharge } \\
\left(\mathrm{mm} \mathrm{yr}^{-1}\right)\end{array}$ & & Galery forest; Miombo dense; Mopane dense; & 3 \\
\hline Excessive & 10 & $>41.29$ & 8 & Semi-decidous open forest; Shifting cultivation; & \\
\hline Little excessive; Good to excessive & 9 & $26.48-41.29$ & 6 & Semi-evergreen (montaneous) forest; & \\
\hline Good; Imperfect to good & 8 & $20.67-26.78$ & 4 & Bare soils & \\
\hline Imperfect & 7 & $16.09-20.67$ & 2 & Built-up areas; Mangrove dense; Mangal open; & 2 \\
\hline Moderate to imperfect & 6 & $<16.09$ & 1 & Semi-evergreen mountainous forest & \\
\hline Imperfect to moderate & 5 & & & Bare Rocks & 0 \\
\hline Moderate & 4 & & & & \\
\hline Moderate to bad; Imperfect to bad & 2 & & & & \\
\hline Bad to very bad; Lakes/lagoons/rivers & 1 & & & & \\
\hline
\end{tabular}

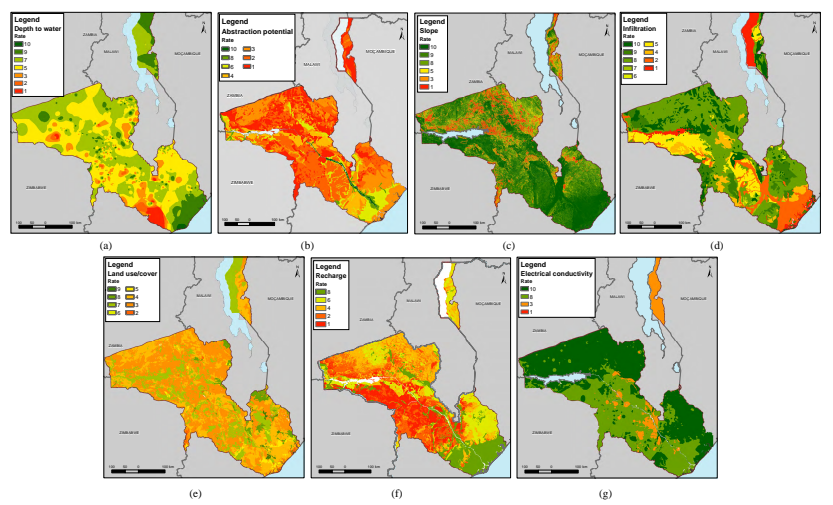

Figure 2. Rating of categories/factors: (a) depth to water table; (b) short-term abstraction potential; (c) slope; (d) soil infiltration; (e) land use/cover; (f) recharge; (g) groundwater quality (EC).

- Aquifer type A - intergranular aquifers (continuous and commonly unconsolidated);

- Aquifer type B - fissured aquifers (discontinuous and commonly consolidated);

- Aquifer type C - areas with local aquifers of limited productivity or areas without significant groundwater resources (intergranular or fissured).
Each aquifer type is associated with a range of "yield classes" from 1 to 3 where the lower number reflects higher shortterm abstraction potential. The chosen rates are presented in Table 1 and applied to create the map in Fig. 2b.

\subsubsection{Recharge $(R)$}

Recharge is probably one of the most important parameters in groundwater planning and management. It is a hydrological process where water moves downward from surface water to groundwater and it gives an indication of the potential for exploitable productivities on the surface. The recharge estimate in this study was based on a weighted combination of the mean annual precipitation (MAP) map, the rated slope map, the rated soil map, and the rated land use/land cover map.

\section{Slope}

The slope map was constructed from the Digital Elevation Model (DEM), at a resolution of approximately $90 \mathrm{~m}$, produced by the NASA Shuttle Radar Topography Mission (SRTM). To construct the rated slope map, flat terrain received a score of 10 (high positive effect on the amount of recharge), and lower scores were awarded whenever the slopes get steeper (lower effect on recharge). The chosen rates (adopted from SWECO, 2004 and Plancenter, 2008) are presented in Table 1 and applied to create the map in Fig. 2c. 


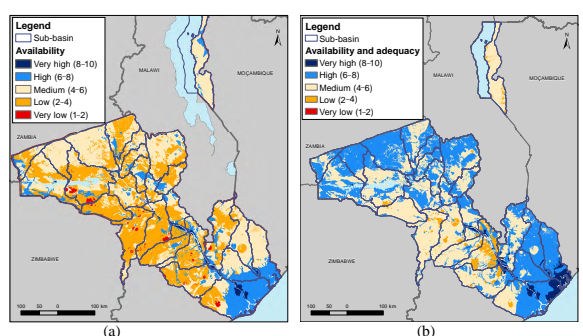

Figure 3. (a) Availability Map and (b) Availability and Adequacy Map.

\section{Soil infiltration}

Information on soils was obtained from the Carta Nacional de Solos de Moçambique at a scale of 1:1000 000. The dataset also contains information on the infiltration properties of the different soil types expressed as a categorical variable ranging from "very bad" to "excessive infiltration". To construct the rated soil map it was assumed that soils with a high infiltration have a high (positive) impact on the aquifer recharge. The chosen rates are presented in Table 1 and applied to create the map in Fig. 2d.

\section{Land use/land cover}

The land use and land cover map at a scale of $1: 250000$ was obtained from the study on the Mozambican agroecological zoning. This factor has an important contribution to the potential of groundwater recharge. Artificial structures such as buildings and pavements of cement or asphalt reduce infiltration. Vegetation, on the other hand, can reduce the energy of the raindrops, which avoids soil compaction by impact force, thus favouring infiltration. Areas densely covered mainly by deeply rooted tree vegetation, promote evaporation at the expense of infiltration (Schilling et al., 2006). The rates, mostly based on literature (Preeja et al., 2011; Senanayake et al., 2016; Suganthi et al., 2013), are presented in Table 1 and applied to create the map in Fig. 2e.

\section{Weighted estimation and rating}

Groundwater recharge was calculated based on information on slopes, soils, land use/land cover and MAP in each subbasin using a weighing procedure. In order to have greater control over the values obtained by the weighing procedure recharge thresholds were stablished for the study area. In this case, there were no previous detailed studies on the recharge potential of the aquifers in the Zambezi Basin. The closest reference is the Hydrogeological map of Mozambique which gives an indication of the value of recharge throughout the country. Thus, recharge thresholds were established based on the hydrogeological characteristics of the basin. In this study, we adopted the following thresholds, i.e. ceiling values for MAP $\left(\operatorname{percMAP}_{n}\right)$ :
- type A aquifer: percMAP $\mathrm{A}_{\mathrm{A}}=16 \%$

- type B aquifer: percMAP $\mathrm{B}=8 \%$;

- type C aquifer: percMAP $\mathrm{C}_{\mathrm{C}}=4 \%$.

The weighted estimate of recharge per sub-basin was calculated as follows (Eq. 3):

$$
\begin{aligned}
& \text { Weighted estimate of recharge }\left(\mathrm{mm} \mathrm{yr}^{-1}\right) \\
& =[(1 \cdot \text { rated slopes })+(2 \cdot \text { rated soils }) \\
& +(3 \cdot \text { rated LU/LC })] / 60 \cdot \text { percMAP }_{n} \cdot \text { MAP. }
\end{aligned}
$$

To validate the recharge estimates, the values obtained in this model were compared with the mean annual runoff (MAR) in each sub-basin, which was estimated using the Pitman model. It was therefore assumed that part of the estimated surface flow refers to the recharge of the aquifers in the basin. In general, MAR values tended to be low with a mean percentage of MAR to MAP over the sub-basins of $10.5 \%$ (Wright, 1992). This value was in line with expected values reported in the scientific literature. At the same time, recharge values tended to be much lower, representing an average percentage of MAR to MAP of $3.4 \%$. This low value reflected well the fact that above $70 \%$ of the basin is composed of base complex aquifers (type $\mathrm{C}$ ) subject to low recharge.

The recharge estimates were rated according to a statistical analysis using the quantiles of their data distribution (Table 1). Figure $2 \mathrm{f}$ shows the recharge rated map.

\subsubsection{Groundwater quality}

To characterize groundwater quality in the Lower Zambezi basin, we used data on electrical conductivity (EC). We chose EC because it is the only parameter most frequently measured in the existing boreholes in the basin and it is therefore more expressive to characterize the groundwater quality at the basin level. The EC map was constructed by interpolating (using IDW) the EC values taking into account the information of the different aquifer types in the basin. EC data for the Niassa Province were not available; therefore this information was obtained from the hydrogeological map and integrated in the EC interpolation.

Ratings of EC were based on fitness for use thresholds (Table 1). These were taken to be $700 \mu \mathrm{S} \mathrm{cm}^{-1}$ (upper limit for domestic consumption), $1500 \mu \mathrm{S} \mathrm{cm}^{-1}$ (irrigation), and $7500 \mu \mathrm{S} \mathrm{cm}^{-1}$ (livestock watering). The resulting rated EC map is shown in Fig. $2 \mathrm{~g}$.

\section{Results}

The final step in producing the map indicating groundwater availability was the use of a weighted sum of the "Depth to water table rated map" (after application of a weighting factor of 5), the "Recharge rated map" (weighting factor of 3.5), 
and the "Short-term abstraction potential rated map" (weighing factor 3). The groundwater availability map is shown in Fig. 3a. To generate the map indicating groundwater availability and adequacy, a weighted sum was used of the three abovementioned maps (with the corresponding weights) and the "Groundwater quality rated map" (weighing factor of 6). The groundwater availability and adequacy map is shown in Fig. 3b. The weights for the categories "Recharge", "Shortterm abstraction potential", and "Groundwater quality" were slightly adjusted compared with previous studies in Mozambique (SWECO, 2004 and Plancenter, 2008) due to the inclusion of category "Depth to water table", which weight was adopted from the DRASTIC method (Aller et al., 1987).

To summarize the results by sub-basin obtained from the "Availability Map" and the "Availability and Adequacy Map", the average (area-weighted) score for each sub-basin was calculated and classified from very low (1-2) through very high (8-10). In general, water availability in the basin was medium to low, with the exception along the lower river margins and in the delta region. The southern margin of the river had on average the least potential, having sub-basins located in zones of low productivity and a corresponding low recharge. The quality of water in these basins was relatively low, possibly due to the occurrence of Sena arkosic sandstones. The northern left bank of the Zambezi River (subbasins number 3, 5, and 7 in Fig. 1) and the sub-basin affluent to Lake Niassa (number 2) had medium availability of groundwater. However, the results for the latter sub-basin were less reliable due to poor data availability. Sub-basins located along the main river course presented on average low groundwater availability. More groundwater was available after the Cahora Bassa dam (sub-basin number 12), and further downstream (sub-basins number 15 and 19). Sub-basins located in the delta $(24,25,26,27)$ had the greatest groundwater availability. In relation to the adequacy of groundwater (quality) for human consumption, the situation generally improved from medium to high. The sub-basins along the southern bank of the main river courses were those having a relatively lower availability and adequacy than the other subbasins.

\section{Conclusions and discussion}

It was concluded that groundwater availability is relatively low in the Zambezi basin. The main reason is that, as calculated from the data in the Hydrogeological map, $77 \%$ of the Zambezi Basin is composed of aquifers of limited productivity (aquifer type $\mathrm{C}$ ). When considering the adequacy of groundwater for human consumption, the situation improved with a large number of sub-basins having a medium to high groundwater availability and adequacy, which were mostly located in the northern bank of the Zambezi river, and the delta region. The potential for groundwater exploitation along the southern bank of the river seemed rather low be- cause there was only low groundwater availability and there were also water quality problems.

The results in this study largely relied on aquifer productivities obtained from the hydrogeological map of Mozambique dated from 1987. An analysis was also carried out to obtain the productivities based on, more recent, borehole data. However, given the quality of these data it was decided that a more intensive data validation procedure was required before using the borehole data for the estimation of aquifer productivities in the basin. Given the paucity of data and the possible limitations in the specificity of the DRASTIC method to the reality of the study area, an improved approach could be to modify the classical model (e.g. VDRASTIC) or combine it with other developed models as in the entropy-weighted fuzzy DRASTIC method (Souleymane and Zhonghua, 2017).

A common problem is the definition of the weights to be assigned to the parameters that are used in determining the relative groundwater potential. There are many techniques that are being tested and proposed ranging from the use of statistical methods based on frequency ratios, the weight of evidence that a given characteristic is more relevant than the other, or the use of the Analytic Hierarchy Process (AHP) (Zeinolabedinia and Esmaeily, 2015). The AHP is considered an innovation that aims at removing subjectivity in selecting and assigning weights to the parameters; however, applying it in this technical sphere of analysis has proven not yet to be sufficiently matured to be adopted in this study. This study used a weighting method for importance (weight of evidence), using similar weights as those developed in a risk analysis method for groundwater contamination (DRASTIC), which has been developed to a great extent in this field of analysis and, therefore, reduces the risk of subjectivity in selecting the weights to be assigned to the parameters under analysis. With regard to the weights used to obtain the "Availability Map", greater weight was given to the "Groundwater depth" category because it has great significance in the prospecting for groundwater for domestic purposes in Mozambique, where most of the population is rural and uses boreholes fitted with manual pumps. The use of an AFRIDEV pump, most used in these projects, is limited for greater depths. Therefore, to introduce this technological condition in the availability, a greater relative weight was given to the water depth category. A lower weight was given the "Recharge" category, which is greater than the weight of the "short-term abstraction potential" given the importance of first identifying the areas with high recharge potential before assessing the viability of water use through abstraction infrastructures.

With regard to the weights used to obtain the "Availability and Suitability Map", the greater weight was given to the "Groundwater quality" category, as this category gives an indication of the suitability of the use intended for the water (in this case for human consumption). 
The recent trends of intensification of mining bring a new reality and challenge in the management of groundwater related to excessive lowering of water levels and the infiltration of acid and supermineralized drainage waters that can reach the water table. The impacts of these new developments need to be assessed and monitored to avoid potential degradation of groundwater quality in the basin. In this study, we used EC to describe groundwater quality as there exists borehole data with good coverage for the whole basin. Data on groundwater quality is still very incipient and does not allow for a spatial view for other relevant quality parameters such as zinc, copper, lead, cadmium and arsenic in those areas where mineralization and mining activities take place.

Finally, the estimated groundwater abstraction potential (short and long-term) as derived from the aquifers' recharge estimates showed that the potential for exploitation of groundwater resources is still very large compared to current uses of the aquifers. Nonetheless, such potential may only be materialized with a proper and intensive control of groundwater use to avoid degradation of the aquifers and ensure groundwater supply on a sustainable basis.

Data availability. Data used in this paper were obtained from various sources including global open data sets. Global data sets include vegetation cover, land use, and a digital elevation model. There are, however, data sets belonging to public entities in Mozambique that can be obtained on request and at a cost, namely the Hydrogeological map of Mozambique at scale 1:100000, rainfall data from the National Meteorological Institute, and soil types from the National Cartographic Centre. Complementary climatic data such as rainfall and temperature, and borehole information are available on request and free of charge from the National Directorate of Water and Resource Management (DNGRH). The resulting maps of this study will be publicly available at the end of the overall study that is part of through the public web site of DNGRH http://www.dngrh.gov.mz.

Competing interests. The authors declare that they have no conflict of interest.

Special issue statement. This article is part of the special issue "Understanding spatio-temporal variability of water resources and the implications for IWRM in semi-arid eastern and southern Africa". It is a result of the IAHS Scientific Assembly 2017, Port Elizabeth, South Africa, 10-14 July 2017.

Acknowledgements. This article was developed within the framework of an ongoing project "Elaboração do plano estratégico para a utilização e desenvolvimento da bacia hidrográfica do rio Zambeze". The authors gratefully acknowledge the funding provided by the National Directorate of Water and Resource Management - Mozambique and the contributions of all members of the project team.
Edited by: Hodson Makurira

Reviewed by: two anonymous referees

\section{References}

Aller, L., Bennett, T., Lehr, J. H., and Petty, R. J.: DRASTIC: A Standardized System for Evaluating groundwater Pollution Potential Using Hydrogeologic Settings, EPA/600/2-87/035, US EPA, Washington, D.C., 1987.

Foster, S. and Tyson, G.: Groundwater development opportunities and management responsibilities - the mission for African Basin Organisations, GWP/ANBO Policy Brief, Global Water Partnership, http://www.gwp.org (last access: January 2018), 2013.

Ganapuram, S., Kumar, G. T. V., Krishna, I. V. M., Kahya, E., and Demirel, M. C.: Mapping of groundwater potential zones in the Musi basin using remote sensing data and GIS, Adv. Eng. Softw., 40, 506-518, 2009.

Plancenter: Joint Maputo River basin water resources study - Moçambique, Swaziland and South Africa, EuropeAid/120802/D/SV/ZA, Groundwater Resources Assessment Report No. 5.1/2007, 2008.

Pondja, E. A., Persson, K. M., and Matsinhe, N. P.: Assessment of coal mine water in Moatize by static and leaching tests, Sustain. Water Resour. Manage., 3, 403-412, 2017.

Preeja, K. R., Joseph, S., Thomas, J., and Vijith, H.: Identification of groundwater potential zones of a tropical river basin (Kerala, India) using remote sensing and GIS techniques, J. Indian Soc. Remote Sens., 39, 83-94, 2011.

Schilling, K., Li, Z., and Zhang, Y.: Groundwater-surface water interaction in the riparian zone of an incised channel, Walnut Creek, Iowa, J. Hydrol., 327, 140-150, 2006.

Senanayake, I. P., Dissanayake, D. M. D. O. K., Mayadunna, B. B., and Weerasekera, W. L.: An approach to delineate groundwater recharge potential sites in Ambalantota, Sri Lanka using GIS techniques, Geosci. Front., 7, 115-124, 2016.

Souleymane, K. and Zhonghua, T.: A novel method of sensitivity analysis testing by applying the DRASTIC and fuzzy optimization methods to assess groundwater vulnerability to pollution: the case of the Senegal River basin in Mali, Nat. Hazards Earth Syst. Sci., 17, 1375-1392, https://doi.org/10.5194/nhess17-1375-2017, 2017.

Suganthi, S., Elango, L., and Subramanian, S. K.: Groundwater potential zonation by remote sensing and GIS techniques and its relation to the groundwater level in the coastal part of the Arani and Koratalai River Basin, Southern India, Sci. Res. J., 17, 8795, 2013.

SWECO: Development of the Pungwe River Basin joint IWRM strategy, in: Monograph Report Annex IV: Groundwater Resources, SWECO Project no. 1150447, 2004.

World Bank: Bacia do Rio Zambeze - Análise de Oportunidades de Investimento Multissectorial, Banco Mundial - Gestão de Recursos Hídricos - Região de África, Washington, 2009.

Wright, E. P.: The Hydrogeology of Crystalline Basement Aquifers in Africa, Geol. Soc. Lond. Spec. Publ., 6, 1-27, 1992.

Zeinolabedinia, M. and Esmaeily, A.: Groundwater Potential Assessment using Geographic Information Systems and AHP Method (Case Study: Baft City, Kerman, Iran), ISPRS Archives, XL-1-W5, 769-774, 2015. 